\title{
Liquid Chromatograph - Mass Spectrophotometer and Anti Uric Acid Potential Studies of Ethyl Acetate Extract of Archidendron bubalinum (Jack) I.C. Nielsen Fruit Seed Shell
}

\author{
Erna Styani ${ }^{1}$, Hanafi, Lilis Sulistiawaty, Candra $\operatorname{Irawan}^{2}$, Imalia \\ Industrial Human Resource Development Board \\ Polytechnic of AKA Bogor \\ Bogor, Indonesia \\ 1'ernasekarboedhi17@gmail.com, ${ }^{2}$ candra_irawan@aka.ac.id
}

\begin{abstract}
This study focused on identifying the types of compounds contained in the ethyl acetate extract of seed shell of Archidendron bubalinum (Jack) I.C. Nielsen (AbJICN ) from Lampung Indonesia using Liquid Chromatograph Mass Spectrophotometer (LC-MS) and determining the potential of anti-uric acid in the identified compounds. The experiment consists of four stages, which are 1) extraction the fruit seed shell of AbJICN using ethyl acetate, 2) phytochemical test, 3) determination of chemical structure using LC-MS and 4) anti uric acid test in vitro by Tri Bromo Hidroksibenzoid Acid (TBHBA) method. The result of phytochemical test found that ethyl acetate extract in fruit seed shell of AbJICN contains compound of flavanoid and terpenoid group. This founding was also supported by the characterization of chemical compounds using LC-MS which indicated the presence of candidates allopurinol and 24 7-Trinitrofluorenone compounds. The decreased uric acid by ethyl acetate extract of fruit seed shell was $1.25 \mathrm{mg} / \mathrm{dL}$ half times compared to standard allopurinol 2,43 $\mathrm{mg} / \mathrm{dL}$. It can be concluded that allopurinol compounds contained in the ethyl acetate extract of seedshell of Archidendron bubalinum (Jack ) I.C. Nielsen potentially became an active anti uric acid substance.
\end{abstract}

Keywords-Seed shell of Archidendron bubalinum (Jack) I.C. Nielsen (AbJICN; Liquid Chromatograph Mass Spectrophotometer (LC-MS); allopurinol; 24 7- Trinitrofluorenone; anti uric acid

\section{INTRODUCTION}

Indonesia is a country that is rich in medicinal plants. Indonesian people have long known and used them as a traditional medicines to prevent or cure a disease. Phytochemicals from plants are biologically active, naturally occurring chemical compounds found in plants, which provide health benefits for humans more than those attributed to macronutrients and micronutrients $[1,2]$. The use of traditional medicines consumed by the Indonesian population is mostly based on experiences passed from one generation to the next. Among traditional medicines that have not been widely studied are traditional medicines for the treatment of gout.

Gout is the final product of purine decomposition in humans. Purine products are converted to uric acid through xanthin in a reaction catalyzed by xanthin oxidase. Then xanthin is oxidized to uric acid in the next reaction which is catalyzed by the enzyme xanthin oxidase. Thus, xanthin oxidase enzyme is an essential target for pharmacological intervention in patients with hyperuricemia and gout disease.

One of the Indonesian plants that has not been used optimally is julang-jaling fruit (AbJICN). The fruit of this plant has different local names such as kabau (Jambi, Palembang, Riau), jering utan (Riau), kabeu (Bengkulu), jering kabau (Sumatra Barat), julang-jaling (Lampung), kerdas atau jering tupai (Malaysia), dan nieng-no (Thailand) [3].

In general, a small part of Indonesian society has used julang-jaling as traditional medicine, namely the fruit is used as a diuretic ingredient, treating smallpox, foot pain, swelling (gout), and coughing. To our knowledge, the phytochemical composition, anti uric acid activity of the "julang-jaling" seed shell have not yet been found. The research phytochemical composition has done at husk of the "julang jaling" for antioxidant and antimicrobe activity[4]. A number of studies have focused on the biological activities of flavonoid and terpenoid compounds, which are antioxidants and free radical scavengers $[5,6]$. Previous studies showed seed of julangjaling contains hypoxanthin compounds that provide stimulation to reduce levels of uric acid.

The use of solvents in extracting AbJICN fruit greatly affects the activity of uric acid. One of the solvents that is widely used in the extraction of natural materials is semi-polar ethyl acetate solvent. Since the terpenoid content of the ethyl acetate extract was probably higher than the $n$-hexane and methanolic extract, we predicted that the biological activity of the ethyl acetate is higher than the other extracts $[7,8,9]$. Based on this, a research will be conducted to find out the types of compounds contained in ethyl acetate extract using LC-MS and to test the anti uric acid potential of the compounds they contain.

The aims of this research is to identify the types of compounds contained in the ethyl acetate extract of seed shell of Archidendron bubalinum (Jack) I.C. Nielsen (AbJICN) from Lampung Indonesia using LC-MS and to determine the potential of anti-uric acid in the identified compounds. 


\section{Methodology}

This study was divided into four stages : 1) extraction the fruit seed shell of AbJICN using ethyl acetate, 2) phytochemical test, 3) determination of chemical structure using LC-MS and 4) anti uric acid potential test in vitro by Tri Bromo Hidroksibenzoid Acid (TBHBA) method.

\section{A. Extraction the Fruit Seed Shell of AbJICN Using Ethyl Acetate}

The seeds of AbJICN were collected from uncultivated farm lands located at Lampung, Sumatera Island, one of province in Indonesia. Te seeds were peeled to separate the seed shells and seed. The seed shells were collected, thoroughly washed and then sun dried for $4 \mathrm{~h}$. The dried seed shells were soaked in ethyl acetate with ratio $1: 10(\mathrm{w} / \mathrm{v})$ and extracted by maceration methods for $24 \mathrm{~h}$. Then, the supernatant was filtered by filter paper. Soaking process was repeated once again in the same sample and the supernatant was filtered. All the supernatant were collected together and concentrated using rotary evaporator at $50^{\circ} \mathrm{C}$.

\section{B. Phytochemical Test [10]}

1) Flavonoids Determination: About $100 \mathrm{mg}$ of ethyl acetate. $5 \mathrm{~mL}$ of the filtrate was mixed with $0.1 \mathrm{mg}$ magnesium powder, $1 \mathrm{~mL}$ concentrated hydrochloric acid and $1 \mathrm{~mL}$ amylalcohol then shaked vigorously. The colour changed to yellow or red orange, indicating the presence of flavonoid.

2) Tannins and Polyphenol Determination: About $100 \mathrm{mg}$ of methanol extracts were extracted with $1 \mathrm{~mL}$ ethanol and 1 $\mathrm{mL}$ distilled water. Te filtrate was mixed with a few drops of $1 \% \mathrm{FeCl}_{3}$ and into another filtrate added with gelatin salt. Then observe the colour changing, if a green or blue or purple colour was appeared, indicating the presence of tannins.

3) Saponins Determination: About $100 \mathrm{mg}$ of ethyl acetate extracts were added with $10 \mathrm{~mL}$ of boiled distilled water, cooled and shaked vigorously for 10 minutes. The foam formation was observed and will be stable if added with a few drops of hydrochloric acid, indicating the presence of saponins.

4) Alkaloids Determination: About $100 \mathrm{mg}$ of ethyl acetat extracts was mixed in $5 \mathrm{~mL}$ of $10 \%$ hydrochloricacid then $\mathrm{pH}$ was adjusted to 8 with dilute ammonia solution. The mixture was added with $20 \mathrm{~mL}$ chloroform and then dried. Te extracts were tested with Dragendorff reagent and Mayer's reagent. The formation of precipitate was indicating the presence of alkaloids.

5) Terpenoid and Steroid Determination: About $100 \mathrm{mg}$ of ethyl acetate extracts were mixed with $25 \mathrm{~mL}$ diethyl etherand shaked vigorously. The diethyl ether layer was separated then added2-3 drops of Lieberman-Burchard reagents. A bluish colour of the interface was formed, indicating positive results for the presence of terpenoids while greenish colour, indicating positive results for the presence ofsteroids.

\section{Determination of Chemical Structure Using LC-MS}

The chemical constituents of the methanol extracts were determinedusing LC-MS. LC-MS analysis was performedusingMariner Bio Spectrometry equipped with a binary pump. The High Performance Liquid Chromatography was interfaced witha Q-TOF Mass Spectrometer filtered with an ESI source. Full-scan modefrom m/z 100 to 1200 was performed with a source temperature of $140^{\circ} \mathrm{C}$. HPLC column Phenomenex $5 \mu \mathrm{C} 8,(150 \times 2 \mathrm{~mm}$ i.d. $)$ was used for the analysis. Solvent was methanol with $0.3 \%$ formic acid. Solvents were delivered at a total flow rate of $0.1 \mathrm{~mL} / \mathrm{min}$. The solvent was run byisocratic elution. The MS spectra were acquired in the positive ion mode. The temperature of the drying gas $\left(\mathrm{N}_{2}\right)$ was $350^{\circ} \mathrm{C}$, at a gas flow rate of $6 \mathrm{~mL} / \mathrm{min}$, and a nebulizing pressure $\left(\mathrm{N}_{2}\right)$ of 25 psi. About $0.5 \mathrm{~g}$ of sample extracts was diluted with methanol and filtered with $0.22 \mu \mathrm{m}$ nylon filter prior to analysis. A $5 \mu \mathrm{L}$ volume of the extracts were injected onto the analytical column for analysis. Te mass fragmentations were identified by using spectrum database for organic compounds in Software and Database Systems (SDBS) application.

\section{Anti Uric Acid Potential Test}

A total of $20 \mathrm{~mL}$ of sample was pipetted into a test tube then $1 \mathrm{~mL}$ of $1^{\text {st }}$ reagent uric acid was added and incubated for 5 minutes then the initial absorbance was measured using a UV-Visible Spectrophotometer at a wavelength of $546 \mathrm{~nm}$. After that $250 \mu \mathrm{L}$ of $2^{\text {nd }}$ reagent uric acid was added and incubated for 30 minutes at $20-25^{\circ} \mathrm{C}$. And then measure the absorbance of the sample solution using UV-Visible Spectrophotometer at a wavelength of $546 \mathrm{~nm}$. Also do measurements on blank. As a standard, uric acid compounds were used in concentrations of less than $6 \mathrm{mg} / \mathrm{dL}$ and absorbance was measured at $546 \mathrm{~nm}$ using UV -Vis Spectrophotometer. The decrease value of uric acid $(\mathrm{mg} / \mathrm{dL})$ was calculated by deduct the uric acid concentration (initial incubation) with uric acid concentration (second incubation).

\section{RESUlT AND DisCUSSION}

\section{A. Extraction the fruit seed shell of AbJICN using ethyl acetate}

Julang-jaling fruit (AbJICN) is one of the Indonesian plants that has not been used optimally.AbJICN has been confirmed for its activity towards many diseases, and recently ethyl acetate fraction of its fruit has been proved to have some activities towards smallpox, foot pain, swelling (gout), and coughing.Semi-polar ethyl acetate solvent is one of the solvents that is widely used and had quite effective abilities in the extraction of natural materials. The use of ethyl acetate as solvents in extracting AbJICN fruit seed shell greatly affects the activity of uric acid.

\section{B. Phytochemical Test of Ethyl Acetate of AbJICN Fruit Seed Shell}

Phytochemical test of ethyl acetate extract of AbJICN fruit seed shell was carried out to determine the chemical compounds contained in the extract so that it was known the 
possibility of active compounds that could be used as health ingredients. The phytochemical test results of ethyl acetate extract of AbJICN can be seen in Table 1.

TABLE 1. PHYTOCHEMICAL COMPOSITION OF ETHYL ACETATE EXTRACT OF AbJICN SEED SHELL

\begin{tabular}{|c|c|c|}
\hline Composition & Test & Results \\
\hline Flavonoid & Shinoda & ++ \\
\hline Tannins & Gelatin & - \\
\hline \multirow{2}{*}{ Total Fenol } & Ferric chloride & - \\
\hline \multirow{2}{*}{ Saponin } & Frothing & - \\
\hline \multirow{2}{*}{ Alkaloid } & Mayer & - \\
\cline { 2 - 3 } & Dragendorff & - \\
\hline \multirow{2}{*}{ Terpenoid } & $\begin{array}{c}\text { Liebermann- } \\
\text { Buchard }\end{array}$ & - \\
\hline
\end{tabular}

Based on Table I, it can be seen that the compounds found in ethyl acetate extract of AbJICN seed shell are terpenoids and flavonoids. In this extract, alkaloids, tannins, total phenols and saponins were not detected. This shows that jellies extracted with ethyl acetate (semi-polar) can be used as an active Ingredients even though the active ingredient functions only in terpenoids and flavonoids.

\section{LC-MS Analysis Ethyl Acetate Extract of AbJICN}

According to the result of the LC-MS chromatogram, two peaks were obtained at 0.44 minutes with a mass candidate of 136.1246 and a retention time of 6.57 with a mass candidate of 315.2242 (Fig 1). Interpretation of the MS spectrum using the spketrum database software for SDBS organic compounds, it was obtained that the compound with mass Candidat 136.1246 was allopurinol.

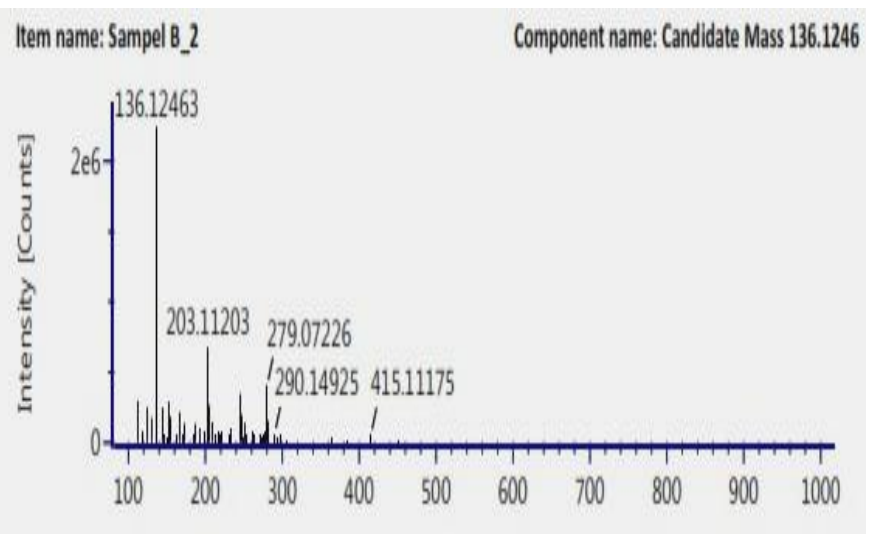

Fig. 1. Chromatogram of LC-MS Ethyl Acetate Extract of AbJICN Seed Shell

Allopurinol is an anti-uric acid compound that can cause hypoxanthine and xanthine to be excreted more in the urine so that the level of uric acid in the blood decreases. The price of $\mathrm{IC}_{50}$ allopurinol shows a value of $0.24 \mu \mathrm{M}$, namely the amount of the concentration of the test material which can result in the inhibition of xanthine oxidase enzyme activity by $50 \%$ (Fig.2). The nature of the allopurinol compound is that it is difficult to dissolve in water so that it can be increased by adding benzoic acid and D-Tartaric Acid. The xanthine oxidase inhibitor allopurinol is the most frequently prescribed medication for the treatment of goutand hyperuricaemia [11,12]. Allopurinol is rapidly absorbed from the gastrointestinal tract and metabolized by xanthine oxidaseto oxypurinol [13], the main metabolite responsible for the pharmacological activity $[14,15]$.

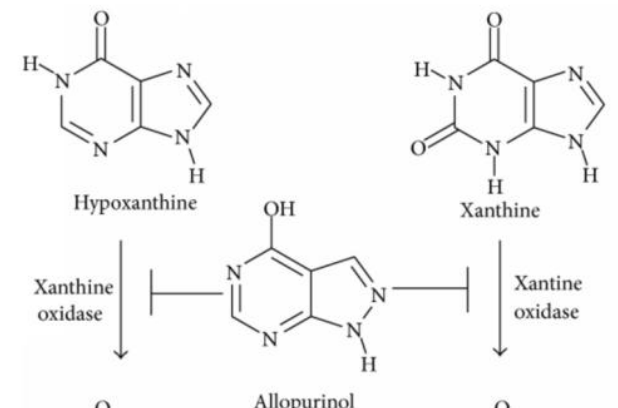<smiles>[Y10]n1c2c(c(=O)[nH]c1=O)N=CNN2</smiles>

Fig.2. Alupurinol, an inhibitor of Xanthine Oxidase

Moreover, another compound was found with mass candidate 315.2242 was 247 -Trinitofluorenone (Fig. 3).

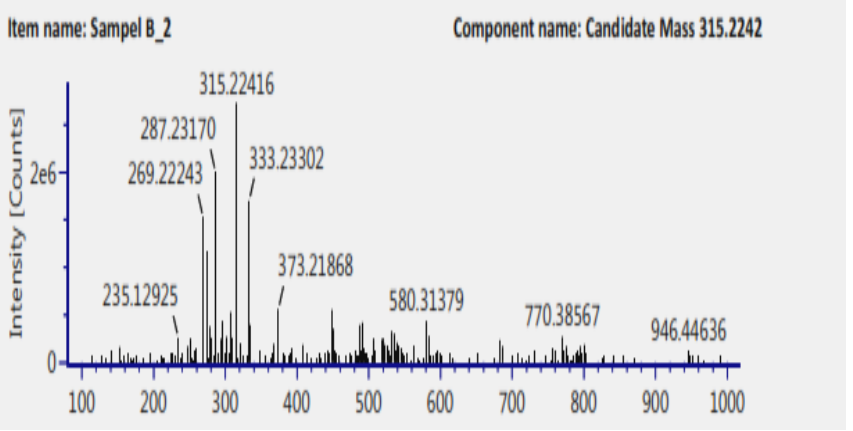

Fig 3. Chromatogram of LC-MS ethyl acetate extract of AbJICN seed shell

2,4,7-Trinitrofluorenone compounds have a melting point of $175.2-176.0^{\circ} \mathrm{C}$. This compound is usually produced from a nitration reaction of fluorenone, 2,3 2,7-dinitrofluorenone, 4 with 2,5-dinitrofluorenone. Stages of the process of adding ingredients can be made from making a mother liquor with water, degrading to form precipitates and crystalline formation from acetic acid [16]. The potential for 2,4,7 trinitrofluorenone compounds for health is not known with certainty, but this 
compound is known as an aromatic nitro group compound that has mutagenic properties [17].

\section{Activity Test for the Anti Uric Acid}

To determine the ability of the ethyl acetate extract of AbJICN in reducing uric acid, anti-uric acid activity was tested using the in vitro method with TBHBA reagent and as a standard used pure uric acid compounds. The Standard curves of uric acid with measured at 546 nmwavelength can be seen in Figure 4.

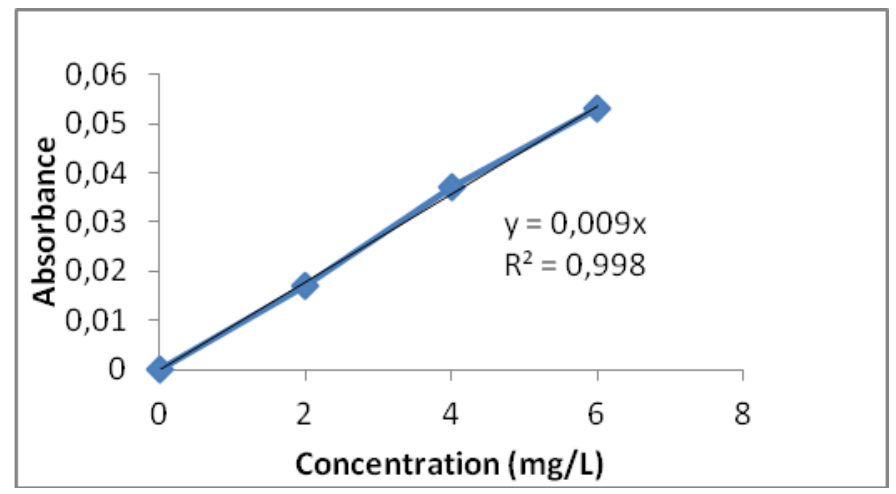

Fig. 4. Standard curves of uric acid measured at 546 nmwavelength

According toFigure 4, it can be inferred that the standard uric acid calibration curve has a linearity curve with the coefficient of determination $\mathrm{R}^{2}=0.998$ which shows a good linierity $\mathrm{r}=0.999$ in the concentration range of 0 to $6 \mathrm{mg} / \mathrm{dL}$. Moreover, the higher concentration of uric acid in the sample, the higher absorbance measured at $546 \mathrm{~nm}$.

The principle of anti-gout test in vitro is uric acid oxidized to allantoin compounds and peroxide compounds by the enzyme uricase. Then the resulting peroxidase compound reacts with 2,4,6-tribromo-3-hydroxybenzoic acid to produce Quinonemin compound which can be measured by spectrophotometer at a wavelength of $546 \mathrm{~nm}$. The initial absorbance will be higher (still contains high uric acid) and will decrease after the second incubation, resulting in a decrease in the concentration of uric acid in units ( $\mathrm{mg} / \mathrm{dL}$ ). The results of the test of anti gout activity in this study can be seen in Figure 5.

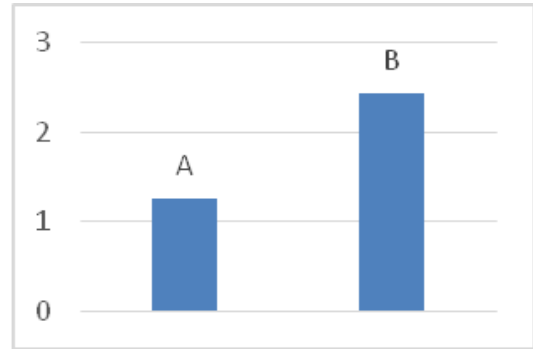

Fig 5. Reduction of Uric Acid Ethyl Acetate Extract of AbJICN (A) and alopurinol standard (B)

According to Figure 5, the decrease in uric acid was 1.25 $\mathrm{mg} / \mathrm{dL}$ half times compared to the standard alpurinol $2.43 \mathrm{mg} /$
$\mathrm{dL}$ and was lower than the activity of kombucha tea $3.02 \mathrm{mg} /$ $\mathrm{dL}$ [18]. This is due to the presence of alpurinol compounds in crude extracts of ethyl acetate fry. The alupurinol compounds contained in the extract are not pure alupurinol so the levels are lower. In the invitro method, alpurinol compounds in the sample will inhibit the uricase enzyme that changes uric acidbecome allantoin so that the level of uric acid in the blood decreases [19].

\section{CONCLUSION}

According to the results of the research that had been done, it can be concluded that the result of phytochemical test found that ethyl acetate extract in fruit seed shell of AbJICN contained compound of flavonoid and terpenoids group. This founding was also supported by the characterization of chemical compounds using LC-MS which indicated the presence of allopurinol candidates and 2,4,7 trinitrofluorenone compounds.

Moreover, the decrease uric acid by ethyl acetate extract of fruit seed shell of AbJICN was $1.25 \mathrm{mg} / \mathrm{dL}$ half times compared to standard allopurinol $2.43 \mathrm{mg} / \mathrm{dL}$. It can be concluded that allopurinol compounds contained in the ethyl acetate extract of fruit seed shell of Archidendron bubalinum (Jack) IC Nielsen potentially became an active anti uric acid substance.

\section{ACKNOWLEDGMENT}

This research was supported by Polytechnic of AKA Bogor, based on the Director Decree Letter of Polytechnic of AKA Bogor No. : 72 / POLTEK. AKA / Kep / 5/2017 about Decision of the Research Team at the Polytechnic of AKA Bogor 2017.

\section{REFERENCES}

[1] L.A.J. Thomson, and R.R. Thaman, "Pometia pinnata (tava)", ver. 2.1. In: Elevitch, C.R. (ed.).Species Profiles for Pacific

[2] H. Nurdin, D. Darwis, and M. Efdi, "Isolation of triterpenoid from stem bark of Pometia pinnata", J. of Chem. and Pharm. Res., vol. 7, pp. 225 227. Nov. 2015.

[3] M.N. Ghazalli, H. Masrom, Y. Omar, S.A. Farhana, "A preliminary flora survey in Gunung Kajang, PulauTioman, Pahang Darul Makmur, Malaysia", Malays Appl Biol. Vol. 43, pp. 17-23, 2014.

[4] C. Irawan, Foliatini, Hanafi, S. Lilis, and S. Maman, "Volatile compound analysis using GC-MS, phytochemical screening and antioxidant activities of the husk of "Julang-Jaling" (Archidendron bubalinum (Jack) I.C Nielsen) from Lampung, Indonesia", Pharmacogn J. ; vol 10, pp. 92-98, January 2018.

[5] Chlopicka J, Pasko P, Gorinstein S, JedryasA, ZagrodzkiP, Total phenolic and total flavonoid content, antioxidant activity and sensory evaluation of pseudocereal breads. LWT Food Sci Tech 2012;46:548555.

[6] J. Grassmann, "Terpenoids as plant antioxidants", Vitam Horm; vol. 72 pp.505, 2005.

[7] S. Selvaraj, C.V. Chittibabu, and B. Janarthanam, "Studies on phytochemical screening, antioxidant activity andextraction of active compound (swertiamarin) from leafextract of Enicostemma littorale", Asian J Pharm Clin Res, vol 7, pp. 240, 2014.

[8] S. Ahmad, S. Ahmad, A. Bibi, M.S. Ishaq, M.S. Afridi, F. Kanwal, M. Zakir, and F. Fatima, "Phytochemical analysis, antioxidant activity, fatty acids composition, and functional group analysis of Heliotropium bacciferum. Sci World J., pp.1-8, 2014. 
[9] E. Iqbal, K.A. Salim, and L.B.L Lim, "Phytochemical screening, total phenolics and antioxidant activities of bark and leaf extracts of Goniothalamus velutinus (Airy Shaw) from Brunei Darussalam”, J King Saud Univ-Sci, vol 27, pp. 224-32, March 2015.

[10] H.O. Edeoga, D.E. Okwu, and B.O. Mbaebre. "Phytochemical Constituent of Some Nigerian Medicinal Plants. Afr Journal of Biotechnology. Vol 4 : 685 - 688, 2005.

[11] T.F. Yu, and A. B. Gutman," Effects of allopurinol (4-hydroxy-pyrazolo (3,4-d)-pyrimidine) on serum and urinary uric acid in primary and secondary gout”, Am. J. Med. Vol. 37, pp. 885-897, 1964.

[12] R.W. Rundles, G.B. Elion, and G.H. Hichings, "Drug and uric acid", Bull. Rheumat. Dis. 16 (1966) 400-405

[13] X. Liu , X.J. Ni, D.W. Shang, M. Zhang, J.Q. Hu, C. Qi, F.T. Luo, and Y.G. Wen, "Determination of allopurinol and oxypurinol in human plasma andurine by liquid chromatography-tandem mass spectrometry", J. of Chromatography, vol. B941, pp. 10-16, 2013.

[14] T. Spector, and D.G. Johns, "Stoichiometric inhibition of reduced xanthine oxidase by hydroxypyrazolo [3,4-d]pyrimidines", J. Biol. Chem. 245) 5079, October 1970.
[15] I.Walter-Sack, J.X. de Vries, C. Kreiner, A. Ittensohn, G. Stenzhorn, A. Voss, and E.Weber, "Disposition and uric acid lowering effect of oxipurinol: comparison of different oxipurinol formulations and allopurinol in healthy individuals, Clin. Invest., vol. 71, pp. 240-246, May 1995

[16] Schmidt and Bauer, " The material reported by these authors as 2,6,7trinitrofluorenone”, Bell, J. Chem. Soc., vol 38, pp. 3760, 1990.

[17] N. Tawari, A. Lele, M. Khambete, and M. Degani, "Mutagenicity Prediction For Nitroaromatic Compounds Using Qstr Modeling”, Intl. J. Pharm. PharmSci, Vol 6, Issue 7, 149-157, 2014.

[18] N.L.P.K. Mardiani, I.B.P. Manuaba, and I.W. Suirta. 2014, "Use ofcombucha tea as Hiperurisemia medicine through reduction of uric acid content and Malondialdehide compound", J. Kim. vol 8, pp. 159165, February 2014.

[19] M. Mazzali, J. Kanellis, L. Han, L. Feng, X.L. Yang, Q. Chen, H.K. Duk, L. Katherine, W.S. Gordon, T. Nakagawa, Y.L. Hui, and J.J. Richard, Hyperuricemia Induces APrimary Renal Arteriolopathy inRats By A Blood Pressureindependent Mechanism. Divisionof Nephrology, Baylor College ofMedicine, Houston, Texas, 2001. 